\title{
Detection of Corynebacterium pseudotuberculosis by SYBR Green Real Time PCR
}

\author{
Jyoti Kumar $^{1 *}$, G.G. Sonawane ${ }^{1}$, S. Jegaveera Pandian ${ }^{1}$ and Rajiv Kumar ${ }^{2}$ \\ ${ }^{1}$ Division of Animal Health, ${ }^{2}$ Division of Animal Genetics and Breeding, ICAR-Central Sheep \\ and Wool Research Institute, Avikanagar 304501, India \\ *Corresponding author
}

\section{A B S T R A C T}

\section{Keywords}

Real time PCR, Corynebacterium pseudotuberculosis, sensitivity, specificity, SYBR green

Article Info

Accepted:

15 January 2019

Available Online:

10 February 2019
Corynebacterium pseudotuberculosis, a Gram positive bacterium is the causative agent of caseous lymphadenitis (CLA), a chronic debilitating disease of sheep, goats and other warm blooded animals. Definite diagnosis of CLA primarily relies on microbiological examination, followed by biochemical identification of isolates. In an effort to facilitate $C$. pseudotuberculosis detection, the present study was undertaken with the aim of evaluating a SYBR Green real time PCR assay targeting ABC transporter gene for the detection of $C$. pseudotuberculosis in DNA isolated from culture and pus samples from sheep and goats. The analytical sensitivity and specificity of the PCR primers were evaluated. The test demonstrated tenfold more sensitivity than conventional PCR and detected down to 100 femtogram of genomic DNA of pure C. pseudotuberculosis. The real-time PCR was found to be specific for $\mathrm{ABC}$ transporter gene of $C$. pseudotuberculosis, as no cross reactivity was detected with a variety of known bacterial isolates. The real time PCR was employed for direct detection of $C$. pseudotuberculosis in pus samples collected from clinically suspected cases of caseous lymphadenitis. It is concluded that, this real time assay may be used as a valuable diagnostic tool for the rapid and specific detection of $C$. pseudotuberculosis in clinical samples, large scale epidemiological studies and clarification of pathogenesis.

\section{Introduction}

Corynebacterium pseudotuberculosis is a Gram-positive bacterium that causes caseous lymphadenitis (CLA), a chronic bacterial disease of sheep, goats and other warm blooded animals (Dorella et al., 2006). The disease during its course causes characteristic suppurative abscessation in the superficial and internal lymph nodes and other internal organs (Williamson 2001). CLA caused by $C$. pseudotuberculosis is a highly contagious disease, and is of significant economic concern for sheep and goat husbandry due to reduced wool and meat quality (Dorella et al., 2006; Guimaraes et al., 2011). 
In India, the detailed epidemiological studies of this disease are lacking, only few published reports of its occurrences among sheep and goats in India is available. The reliable control strategy for this disease would be rapid and early identification and removal of the infected animals from the herd or flock. The laboratory detection of $C$. pseudotuberculosis is done by microbiology, biochemical, serological and nucleic acid based detection methods (Baird and Fontaine 2007; Guimaraes et al., 2011; Quinn et al., 2011)). Serological tests are not so conclusive and suffer from cross reactivity with other bacteria (Manning et al., 2007).

Polymerase chain reaction (PCR) based methods have been used frequently for direct detection of microbes in culture, clinical and postmortem samples. PCR based assay has many advantages compared to traditional diagnostic methods. A well designed PCR is highly sensitive, rapid and specific. Furthermore, real time PCR has additional advantages with respect to rapidity and sensitivity. The present study was to evaluate a real-time assay based on SYBR green for detection of $C$. pseudotuberculosis in bacterial cultures which can also be applied for direct detection in clinical or postmortem samples of CLA suspected animals.

\section{Materials and Methods}

\section{Samples and bacterial DNA}

A total of twenty archived pus samples collected from clinically suspected cases of caseous lymphadenitis in sheep and goats were included for evaluation of the real time PCR assay. A homogenous suspension of pus samples was made in $1 \mathrm{ml}$ of autoclaved distilled water and transferred in $1.5 \mathrm{ml}$ sterile plastic tubes for isolation of DNA. The DNA extracted from a variety of known bacterial isolates from sheep and available in our laboratory was included to evaluate the specificity of the PCR primer. It included DNA samples from Mannheimia haemolytica, Pasteurella multocida, Bibersteinia trehalosi, Escherichia coli, Staphylococcus aureus, C. pseudotuberculosis, and Rhodococcus equi (strain VTCC BAA67, courtesy ICARNational Centre for Veterinary Type Culture Centres, Hisar, India).

\section{DNA extraction}

The Genomic DNA was extracted from pure culture of C. pseudotuberculosis and pus samples using Qiagen DNeasy Blood and Tissue kit, according to manufacturer's instruction. The DNA content was quantified by use of a nanodrop (Quawell Technology Inc., USA). The quantified DNA samples were stored at $-20{ }^{\circ} \mathrm{C}$ till further use in the molecular assay.

\section{Primers and PCR}

Oligonucleotide primers targeting Putative oligopeptide/ dipeptide $\mathrm{ABC}$ transporter gene specific to $C$. pseudotuberculosis were synthesized from Sigma. Sequences of the primers used in this study were forward $5^{\prime}$ CCTTACCGAGACAACGTCAT $\quad-3^{\prime}$ and reverse 5'- GCCTGGTGCTTATCATTGAT 3' (D'Afonseca et al., 2010). The $10 \mu \mathrm{l}$ conventional PCR reaction mixture consisted of $200 \mu \mathrm{M}$ of dNTP mix, $0.2 \mu \mathrm{M}$ of each primer, $1.5 \mathrm{mM}$ of $\mathrm{MgCl}_{2}$ and $0.5 \mathrm{U}$ of Taq DNA Polymerase (Sigma-Aldrich, USA) in 1X PCR buffer. The optimized thermal cycling conditions were as follows; initial denaturation step at $95{ }^{\circ} \mathrm{C}$ for $5 \mathrm{~min}$ followed by 40 cycles of denaturation at $95^{\circ} \mathrm{C}$ for $30 \mathrm{~s}$, $54{ }^{\circ} \mathrm{C}$ for $45 \mathrm{~s}$, and $72{ }^{\circ} \mathrm{C}$ for $45 \mathrm{~s}$, and a final extension at $72{ }^{\circ} \mathrm{C}$ for $10 \mathrm{~min}$. Negative control was also included during the PCR reaction set up. The amplicon of $285 \mathrm{bp}$ was visualized after electrophoresis through $2 \%$ agarose gel containing ethidium bromide (Sambrook and Russell, 2001). 
For sequencing of the representative amplicon standard PCRs were run and PCR products $(60 \mu 1)$ were resolved on $2 \%$ agarose gel. The specific sized bands were excised from agarose gel under UV light and were subsequently purified using MinElute Gel Extraction Kit (Qiagen). The purified products were sequenced (Xcelris Genomics, India) and compared with the published sequences available in the NCBI online database.

\section{Real time PCR}

The SYBR green real-time PCR assay was performed over DNA samples from cultures and pus samples with the same primer set as used for conventional PCR using StepOnePlus Real-Time PCR System (Applied Biosystems, USA). Each $10 \mu \mathrm{l}$ PCR reaction mix had $0.10 \mu \mathrm{l}$ each of forward and reverse primers (100 $\mathrm{nm}$ final concentration), $1 \mu \mathrm{l}$ template DNA, and $5 \mu \mathrm{l} 2 \mathrm{X}$ Maxima SYBR Green/ROX qPCR Master Mix (Thermo scientific, USA) and $3.8 \mu$ l nucleasefree PCR grade water. The SYBR green real time PCR conditions were as follows: initial denaturation at $95{ }^{\circ} \mathrm{C}$ for $10 \mathrm{~min}$, followed by 40 cycles of $95{ }^{\circ} \mathrm{C}$ for $15 \mathrm{~s}$ and annealing/extension at $60{ }^{\circ} \mathrm{C}$ for $60 \mathrm{~s}$.

\section{Sensitivity and specificity of the PCR and real time PCR}

The analytical sensitivities of the primers used in real-time PCR and conventional PCR were carried out by 10 fold dilution of the DNA isolated from well characterized and pure C. pseudotuberculosis isolate. Specificity of the real-time PCR and conventional PCR assays were assessed by performing the reaction with $C$. pseudotuberculosis, as well as DNA from a variety of bacteria isolated from sheep and goats.

\section{Results and Discussion}

Infection caused by $C$. pseudotuberculosis, remains a cause of concern for sheep and goat farming system globally (Baird, 1997; Williamson, 2001; Paton et al., 2003; Dorella et al., 2006). Because of highly contagious nature of the agent, test and cull strategy has been the suggested method to control the spread of the disease (Baird, 1997; Williamson, 2001). As conventional methods are not always forthright, the improved method of rapid and specific detection may facilitate the control of CLA.

In the current study, we evaluated a sensitive and specific SYBR green real time assay for the detection of $C$. pseudotuberculosis. The performance of an assay was tested for its specificity and sensitivity. To obtain a good sensitivity and specificity of the assay selection of appropriate target gene and primers must be considered. In the current study, we chose the ABC transporter gene as a target for the detection of $C$. pseudotuberculosis. The ABC transporter gene is reported to be a conserved and associated with virulence and pathogenesis in C. pseudotuberculosis infection (Ruiz et al., 2011). A 10-fold dilution serial dilution of DNA from $10 \mathrm{ng}$ to $1 \mathrm{fg}$ per reaction were prepared and used to estimate limit of detection also called as sensitivity of the PCR tests (Fig. 1).

Under the described reaction conditions $(1 \mu \mathrm{l}$ of DNA extract per $10 \mu \mathrm{l}$ assay), the detection limit of the SYBR green real time PCR test using DNA from pure bacterial culture was $100 \mathrm{fg}$ (Fig. 1a). While the detection limit of the conventional PCR was 1 pg per assay (Fig. 1b). Therefore, the real time PCR was ten times more sensitive than the conventional PCR. 
Fig.1 Analytical sensitivity of SYBR green real-time PCR and conventional PCR

a.

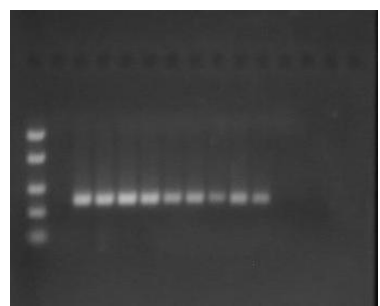

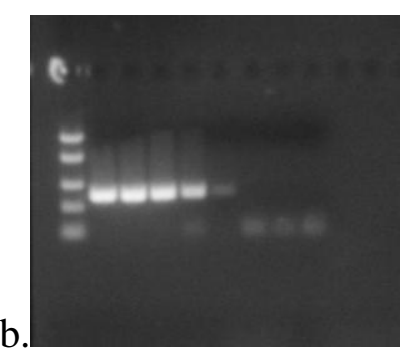

(a). Agarose gel electrophoresis of SYBR green real-time PCR amplicon (285 bp) showing sensitivity upto $100 \mathrm{fg}$. Amount of C. pseudotuberculosis DNA in L1=FastRuler Low Range DNA ladder (\#SM1103), = L2= negative control, L3=100 ng Sheep isolate, L4=50 ng goat isolate, L5=30 ng of stock DNA used for dilution, L6= $10 \mathrm{ng}$, L7= $1 \mathrm{ng}, \mathrm{L} 8=100 \mathrm{pg}, \mathrm{L} 9=10 \mathrm{pg}, \mathrm{L} 10=1 \mathrm{pg}, \mathrm{L} 11=100 \mathrm{fg}, \mathrm{L} 12=10 \mathrm{fg}$ and $\mathrm{L} 13=1 \mathrm{fg}$.

(b). Agarose gel electrophoresis of conventional PCR product (285 bp) showing sensitivity upto $1 \mathrm{pg}$. Amount of $C$. pseudotuberculosis DNA in L1= FastRuler Low Range DNA ladder (\#SM1103), L2= 10 ng, L3= $1 \mathrm{ng}, \mathrm{L} 4=100 \mathrm{pg}$, $\mathrm{L} 5=10 \mathrm{pg}, \mathrm{L} 6=1 \mathrm{pg}, \mathrm{L} 7=100 \mathrm{fg}, \mathrm{L} 8=10 \mathrm{fg}$ and $\mathrm{L} 9=$ negative control

Fig.2 Representative Melt curve showing presence of single specific real time PCR product specific to C. pseudotuberculosis

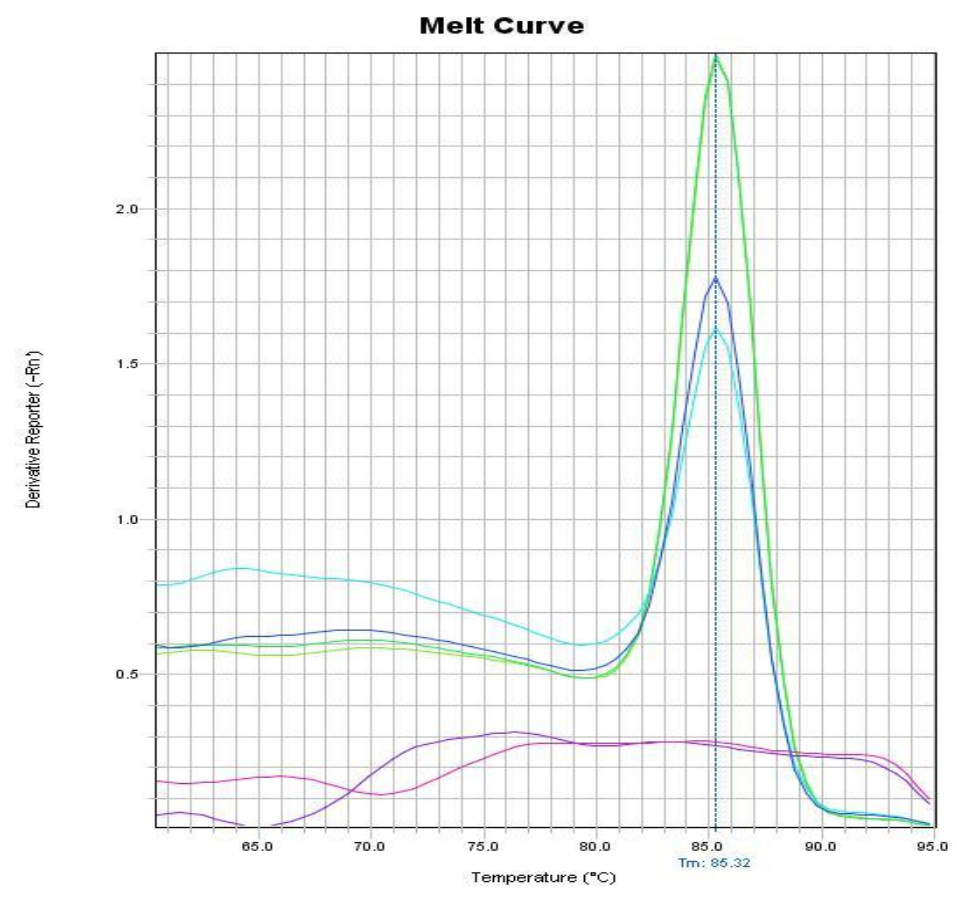

The limits of detection of many other PCR tests used for $C$. pseudotuberculosis have not been determined. In another study by Pacheco et al., 2006, the sensitivity of the multiplex PCR for genomic DNA from pure C. pseudotuberculosis culture was $1 \mathrm{pg}$, similar as in our conventional PCR assay.

On evaluation of specificity using DNA from different bacterial species (P. multocida, $E$. 
coli, S. aureus, M. haemolytica, B.trehalosi, $R$. equi) other than $C$. pseudotuberculosis, real-time amplification was seen only in DNA isolated from C. pseudotuberculosis. Similar result for specificity has been reported in a study targeting $r p o B$ and pld gene of $\mathrm{C}$. pseudotuberculosis (Pacheco et al., 2006; Khamis et al., 2004). False positive signals observed later in the amplification cycles were verified using melt curve analysis (Fig. 2). Alternatively, the agarose gel electrophoresis of the real time PCR amplification products was used to preclude non-specific amplification signals emanating from low molecular weight DNA like primer dimers. The specificity of the assay can be confirmed by nucleotide sequencing of the amplified products. Nucleotide sequence of the $\mathrm{ABC}$ transporter amplicon showed high degree of similarity (98-100 \%) with the published sequence in the NCBI database. None of the other bacterial strains showed amplification products indicating the high degree of specificity of this assay (D'Afonseca et al., 2010). Only positive control DNA produced right amplification with a melting peak at approximately $85.32^{\circ} \mathrm{C}$ which is consistent with that expected for targeted $\mathrm{ABC}$ transporter gene amplicon of $C$. pseudotuberculosis under current reaction conditions (Fig. 2). Same result for specificity testing was observed for the conventional PCR also.

A total of twenty pus samples were tested for the presence of C. pseudotuberculosis. Out of these, DNA from twelve pus samples was found positive for C. pseudotuberculosis by real time PCR. The conventional PCR also detected the same pus samples positive for C. pseudotuberculosis as detected positive by real time PCR. However, with this limited sample size and that too all from clinically obvious cases, the superiority of the real time PCR over conventional PCR could not be conclusively established or estimated in percent terms. The improved detection with SYBR green dye chemistry based real time PCR is obvious as its sensitivity being on higher side and need further evaluation over a large number and variety of tissue and/or clinical samples.

Speedy and sensitive detection of $C$. pseudotuberculosis is of significant clinical importance. The specific and highly sensitive SYBR green PCR assay performed in the present work may be suitable as a rapid and economic diagnostic tool to identify the sheep carrying C. pseudotuberculosis. As the clinical sample size was relatively small, this promising assay needs to be tested on a large number of samples and over a variety of samples to further assess its suitability in the field to enable its adoption for the screening and early detection of diseased/carrier animals in a healthy herd and further to control the CLA.

\section{Acknowledgments}

The authors are thankful to the Director, ICAR-CSWRI, Avikanagar for providing necessary facilities to carry out this study. The work has been conducted in the Institute project on Assessment of changing epidemiology and management of economically important sheep and goat diseases.

\section{References}

Baird, G., 1997. Caseous lymphadenitis: an increasing cause for concern. Veterinary Record, 140, 611.

Baird, G.J. and Fontaine, M.C., 2007. Corynebacterium pseudotuberculosis and its role in ovine caseous lymphadenitis. Journal of Comparative Pathology, 137, 179-210.

D'Afonseca, V., Prosdocimi, F., Dorella, F.A., Pacheco, L. G. C., Moraes, P. M., Pena, 
I., Ortega, J. M., Teixeira, S., Oliveira, S. C., Coser, E. M., Oliveira, L. M., Oliveira, G. C., Meyer, R., Miyoshi, A. and Azevedo, V., 2010. Survey of genome organization and gene content of

Corynebacterium pseudotuberculosis. Microbiology Research, 165, 312-320.

Dorella, F.A., Pacheco, L.G.C., Oliveira, S.C., Miyoshi, A. and Azevedo, A., 2006. Corynebacterium pseudotuberculosis: microbiology, biochemical properties, pathogenesis and molecular studies of virulence. Veterinary Research, 37, 201-218.

Fontaine, M. C. and Baird, G. J., 2008. Caseous lymphadenitis. Small Ruminant Research, 76, 42-48. Guimaraes, A.S., Carmo, F.B., Pauletti, R.B., Seyffert, N., Ribeiro, D., Lage, A.P., Heinemann, M.B., Miyoshi, A., Azevedo, V. and Gouveia, A.M.G., 2011. Caseous lymphadenitis: epidemiology, diagnosis, and control. Institute of Integrative Omics and Applied Biotechnology Journal, 2(2), 33-43.

Khamis, A., Raoult, D. and La Scola, B., 2004. rpoB gene sequencing for identification of Corynebacterium species. Journal of Clinical Microbiology, 42, 3925-3931.

Manning, E. J. B., Cushing H. F., Hietala, S and Wolf, C. B., 2007. Impact of Corynebacterium pseudotuberculosis infection of serologic surveillance for Johne's disease in goats. Journal of Veterinary Diagnostic Investigation,19, 187-190
Pacheco, L. G. C., Pena, R. R., Castro, T. L. P., Dorella, F. A., Bahia, R. C. Carminati, R., Frota, M. N. L., Oliveira, S. C., Meyer, R., Alves, F. S. F., Miyoshi, A. and Azevedo, V., 2007. Multiplex PCR assay for identification of Corynebacterium pseudotuberculosis from pure cultures and for rapid detection of this pathogen in clinical samples. Journal of Medical Microbiology, 56, 480-486.

Paton, M. W., Waker, S. B., Rose, I. R. and Watt, G. F., 2003. Prevalence of caseous lymphadenitis and usage of caseous lymphadenitis vaccine in sheep flocks. Australian Veterinary Journal, 81, 91-95.

Quinn, P. J., Markey, B. K., Leonard, F. C., Hartigan, P., Fanning, S. and FitzPatrick, E. S., 2011. Veterinary microbiology and microbial disease, 2nd edition. Wiley-Blackwell, West Sussex, UK.

Ruiz, J. C., D'Afonseca, V., Silva, A., Ali, A., Pinto, A. C., Santos, A. R.et al., 2011. Evidence for reductive genome evolution and lateral acquisition of virulence functions in two Corynebacterium pseudotuberculosis strains. PLoS ONE, 6(4), e18551.

Sambrook, J. and Russell, D. W. 2001. Molecular cloning: A laboratory manual, 3rd edition. Cold Spring Harbor Laboratory Press, New York.

Williamson, L.H., 2001. Caseous lymphadenitis in small ruminants. Veterinary Clinics of North America: Food Animal Practice, 17,359-371.

\section{How to cite this article:}

Jyoti Kumar, G.G. Sonawane, S. Jegaveera Pandian and Rajiv Kumar. 2019. Detection of Corynebacterium pseudotuberculosis by SYBR Green Real Time PCR. Int.J.Curr.Microbiol.App.Sci. 8(02): 1693-1698. doi: https://doi.org/10.20546/ijcmas.2019.802.198 